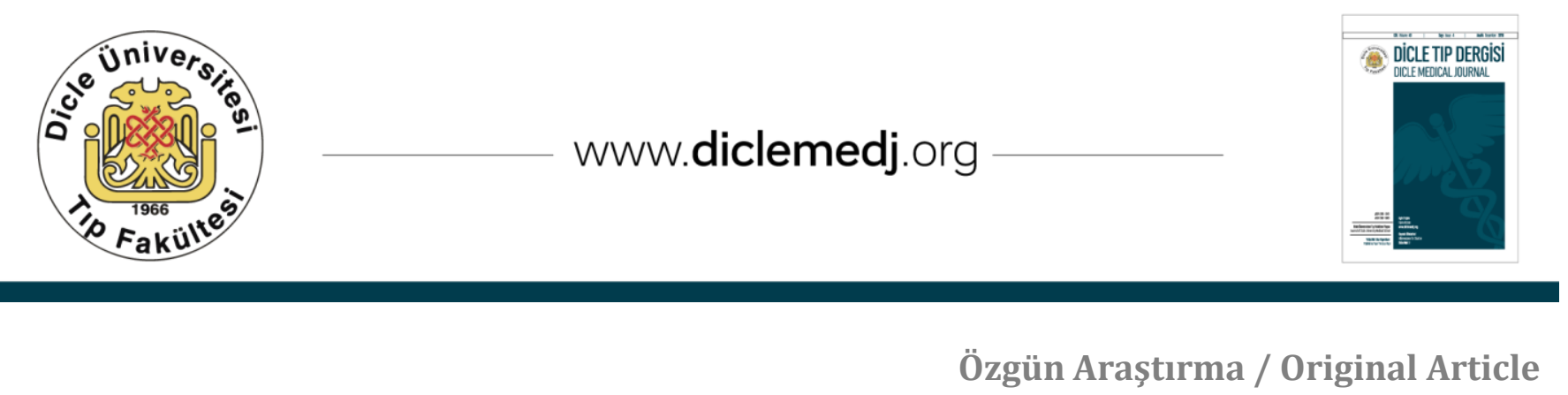

\title{
Parkinson Hastalığında Retina Sinir Lifi Tabakası ve Makula Kalınlığının Değerlendirilmesi
}

\author{
Funda Dikkaya1', Ahmet Özkök², Şakir Delil³ \\ 1 İstanbul Medipol Üniversitesi, Göz Hastallkları Ana Bilim Dalı, İstanbul, Türkiye ORCID: 0000000323122521 \\ 2 Miller Eye Center, Rockford, IL, USA. ORCID: 0000-0003-4369-6346 \\ 3 Batı Bahat Hastanesi, Nöroloji Bölümü, İstanbul Türkiye ORCID: 0000-0001-5011-8929
}

Geliş: 16.04.2018, Revizyon: 13.06.2018, Kabul Tarihi: 16.07.2018

Öz

Amaç: Parkinson hastalarını retina sinir lifi tabakası (RSLT) ve makula kalınlıkları yönünden incelemek ve sağlıklı kontrol grubu ile karşılaştırmak

Yöntem: Parkinson tanısı alan yaş ortalaması 69,2 $\pm 8,2$ yıl olan 25 hasta ve sistemik hastalık öyküsü bulunmayan yaş ortalaması 67,2 $\pm 7,1$ yıl olan 19 hasta göz bulguları açısından değerlendirildi. Hastalara Optik Koherens Tomografi (OKT) ile RSLT ve makula kalınlık ölçümleri yapıldı. Gruplar elde edilen veriler açısından Student $t$ testi ile karşılaştırıldı.

Bulgular: İnferior kadran RSLT Parkinson grubunda 133,1 $\pm 19,3 \mu \mathrm{m}$, kontrol grubunda ise $145,1 \pm 19,6 \mu \mathrm{m}$ olarak ölçüldü. İnferior kadran RSLT'deki bu incelme istatistiksel olarak anlamlı bulundu ( $p=0,049)$. Diğer kadran RSLT ve makula kalınlıklarında gruplar arası fark tespit edilmedi.

Sonuç: Çalışmamızda Parkinson hastalarında inferior kadran RSLT kalınlığında azalma tespit ettik. Parkinson hastalarında retinadaki dopamin miktarında meydana gelen azalma ganglion hücre kaybına yol açarak RSLT kalınlığında incelmeye neden olabilmektedir.

Anahtar Kelimeler: Parkinson hastalığı, retina sinir lifi tabakası, makula kalınlığı, optik koherens tomografi.

DOI: $10.5798 /$ dicletip. 457264

Yazışma Adresi / Correspondence: Funda Dikkaya, İstanbul Medipol Üniversitesi, Medipol Mega Hastanesi, Göz hastalıkları Ana Bilim Dall, 34214, Bağcılar, İstanbul, Türkiye e-mail: fundadikkaya@hotmail.com 


\title{
Evaluation of the retinal nerve fiber layer and macular thickness in patients with Parkinson's disease
}

\begin{abstract}
Objective: To investigate the retinal nerve fiber layer (RNFL) and macular thickness in patients with Parkinson's disease and to compare the results with healthy control group.

Methods: 25 Parkinson's patients with the mean age of $69.2 \pm 8.2$ years and 19 healthy control subjects with the mean age of 67.2 \pm 7.1 years were included in the study. Patients received RNFL and macular thickness measurements with optical coherence tomography (OCT). Values were compared between groups with student's t-test.

Results: RNFL in inferior quadrant was $133.1 \pm 19.3 \mu \mathrm{m}$ for Parkinson's disease group, $145.1 \pm 19.6 \mu \mathrm{m}$ for control group. The difference was statistically significant $(\mathrm{p}=0.049)$. There was no statistical significant difference between other quadrant RNFL and macular thickness.

Conclusion: We found decrease in inferior quadrant RNFL in patients with Parkinson's disease. Decreased dopamine content of the retina in Parkinson disease may cause RNFL thinning via ganglion cell loss.
\end{abstract}

Keywords: Parkinson's disease, retinal nerve fiber thickness, macular thickness, optical coherence tomography.

\section{GíRiş}

Parkinson hastalığı, substansia nigra'da dopaminerjik nöronların dejenerasyonu ile karakterize santral sinir sisteminin nörodejeneratif bir hastalığıdır. Dopaminerjik yolaktaki dejenerasyona bağlı olarak motor sistemin yanında motor olmayan sistemlerde de etkilenme görülmektedir. Vizüel sistem de etkilenen sistemlerden biridir ${ }^{1}$.

Retinada özellikle amakrin ve interpleksiform hücrelerde bulunan dopamin, nöromodülatör ve nörotransmitter rol oynamaktadır. Parkinson hastalarında retinada dopamin miktarında azalma olduğu gösterilmiştir ${ }^{2}$. Kontrast duyarlılığında azalma, renkli görme bozuklukları, göz kırpma refleksinde azalma ve kuru göz bu hastalarda bildirilmiş olan vizüel sistem bozukluklarındandır ${ }^{3,4}$.

Optik koherens tomografi (OKT) retinanın ve optik sinirin non-kontakt, non-invaziv bir şekilde yüksek çözünürlükte tomografik kesit görüntülerinin elde edilmesini sağlayan bir araçtır. Aynı zamanda retina tabakalarını ayırt ederek retina sinir lifi tabakası (RSLT) kalınlığının ölçülebilmesine olanak sağlar.
Alzheimer hastalığı ve Multiple sklerozis gibi nörodejenaratif hastalıklarda optik sinir etrafındaki RSLT kalınlığında incelme tespit edilmiş olup, RSLT kalınlık ölçümünün bu hastalıkların tanı ve takibinde kullanılabileceği düşünülmüștür5,6. Parkinson hastalarında RSLT kalınlığını inceleyen çalışmaların bir kısmında incelme tespit edilirken bir kısmında değişiklik olmadığı saptanmıştır7-14.

Biz de çalışmamızda Parkinson hastalarını RSLT ve makula kalınlıkları yönünden incelemeyi ve sağlıklı kontrol grubu ile karşılaştırmayı hedefledik.

\section{YÖNTEMLER}

Çalışmamız kapsamında idiopatik Parkinson tanısı alan 25 hasta ve sistemik hastalık öyküsü bulunmayan 19 hasta prospektif olarak değerlendirildi. Çalışma için 7 Şubat 2012 tarihli etik kurul toplantısında onay alındı. Çalışmada Helsinki Deklarasyonu Prensiplerine sadık kalındı ve çalışmaya katılan hastalardan bilgilendirilmiş onam formu alındı.

İdiopatik Parkinson tanısı UK Brain Bank kriterlerine göre konuldu ${ }^{15}$. Hem Parkinson hasta grubu hem de kontrol grubu için, glokom, 
makula dejenerasyonu, üveit, retinal ve koroidal vasküler hastalık, geçirilmiş retinal cerrahi, oküler travma ya da optik nöropati öyküsü olan, RSLT kalınlığı ölçümünü engelleyebilecek optik sinir başı veya retina anomalisi olan kişiler çalışmaya dahil edilmedi. Hastaların glokom ilacı kullanım öykülerinin olmaması, göz içi basınçlarının 21 mm Hg'yi geçmemesi, tipik glokomatöz optik nöropati bulgularının olmaması ile glokom tanısı dışlandı.

Tüm olgularda Snellen eşeliyle görme keskinliği, biyomikroskopik muayene ve dilatasyon sonrası fundoskopik muayenenin yanında Goldmann aplanasyon tonometresi (AT-900; Haag-Streit AG, Koniz, Switzerland) kullanılarak göz içi basınç ölçümleri ve OKT ile RSLT ve makula kalınlık ölçümleri yapıldı.

Retina sinir lifi tabakası kalınlık ölçümleri, OKT (OPKO/OTI Spectral OCT/SLO, OPKO Health, Inc. Miami, Florida) cihazıyla yapıldı. Her olguda peripapiller RSLT kalınlığı ölçümleri için, $3.4 \mathrm{~mm}$ çaplı tarama halkası optik disk santralde olacak şekilde yerleştirildi. Peripapiller RSLT ölçümüyle süperior, inferior, nazal ve temporal kadranların kalınlıkları ayrı ayrı, bununla birlikte 4 kadranın ortalama kalınlığı kantitatif olarak saptanarak kaydedildi (Resim 1).

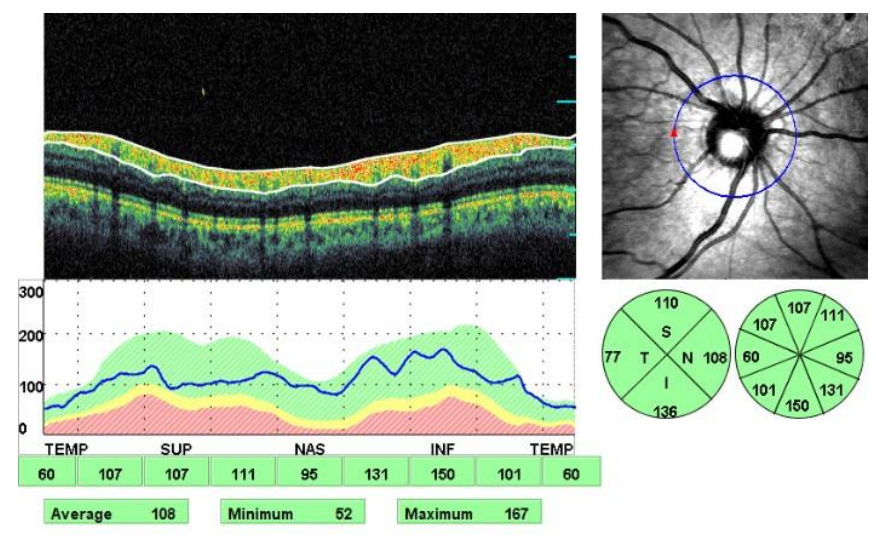

Resim 1. Retina sinir lifi tabakasının (RSLT) OKT ile ölçümü. A. RSLT'nin demonstrasyonu B. Peripapiller RSLT kalınlığı ölçümü için $3.4 \mathrm{~mm}$ çaplı tarama halkasının gösterimi C. RSLT'nin kalınlık haritası. D. RSLT'nin alt bileşenlerinin süperior (S), temporal (T), nazal $(\mathrm{N})$ ve inferior (I) kalınlıklarının çark grafik şeklinde dökümü.
Cihazda makulanın topografik kalınlık haritası $1 \mathrm{~mm}$ çaplı fovea alanı, $3 \mathrm{~mm}$ çaplı parafoveal alan (temporal, süperior, nazal, inferior kadranlar), $5 \mathrm{~mm}$ çaplı perifoveal alan (temporal, süperior, nazal, inferior kadranlar) şeklinde ETDRS'nin tanımladığı 9 zon haritası ile gösterilmektedir (Resim 2).

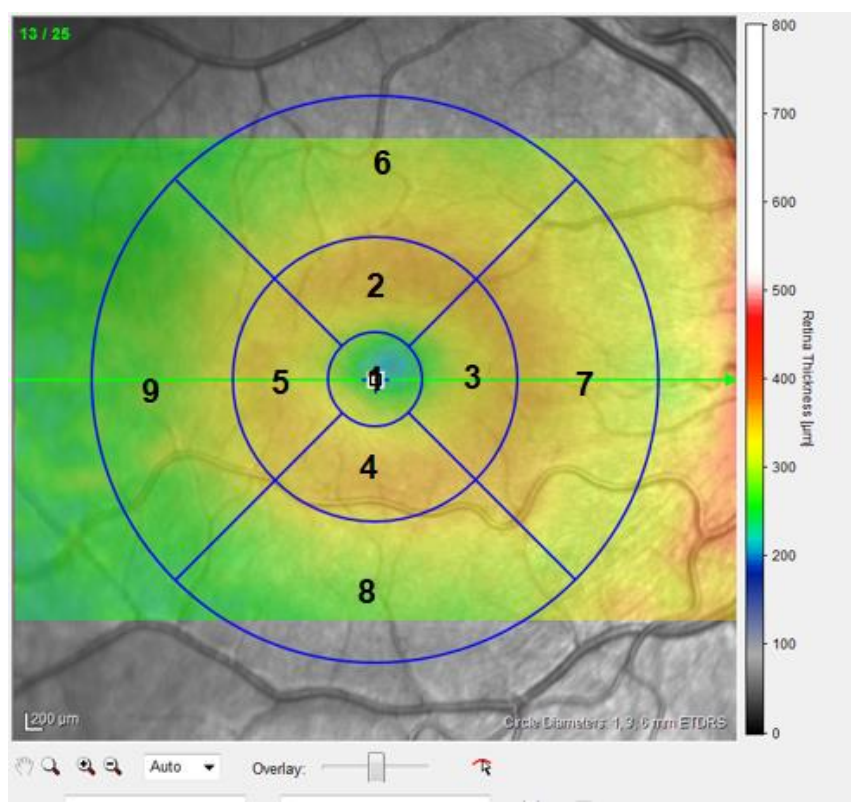

Resim 2. Makulanın 9 zon haritası ile gösterilmesi: 1.santral foveal alan 2. Süperior parafoveal alan 3.Nazal parafoveal alan 4.İferior parafoveal alan 5.Temporal parafoveal alan 6 . Süperior perifoveal alan 7. Nazal perifoveal alan 8. İnferior perifoveal alan 9. Temporal perifoveal alan.

Çalışma kapsamında tüm bu zonlardaki ortalama retinal kalınlık ölçümleri değerlendirildi. Hastalardan ikişer ölçüm alınarak ortalamaları hesapland.

İstatistiksel Analiz

Verilerin değerlendirilmesi "Statistical Package for Social Sciences" (SPSS) programı ile bilgisayar ortamında yapıldı. İki grup arasında tanımlayıcı parametreler Ki-kare Test ile karşılaştırılırken, sayısal parametrelerin karşılaştırılmasında Student t-testi kullanıldı. Testlerin değerlendirilmesinde " $p$ " değerinin 
0.05'den küçük olması $(\mathrm{p}<0.05)$ istatistiksel olarak anlamlı kabul edildi.

\section{BULGULAR}

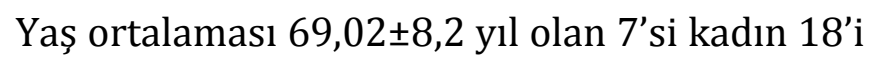
erkek 25 idiopatik Parkinson hastası ve yaş ortalaması $67,2 \pm 7,1$ yıl olan 9'u kadın 10'u erkek 19 sağlıklı olgu çalışma kapsamında değerlendirildi. Gruplar arasında cinsiyet ve yaş açısından istatistiksel olarak anlamlı fark izlenmedi (sirasiyla $\mathrm{p}=0.194 ; \mathrm{p}=0.394$ ). Parkinson hastalarının ortalama hastalık süresi $7,84 \pm 6,04$ yıl idi. Göz içi basınç değerleri Parkinson grubunda ortalama $14,1 \pm 2,8 \mathrm{mmHg}$, kontrol grubunda $13,5 \pm 2,5 \mathrm{mmHg}$ olarak bulundu ( $\mathrm{p}=0.434)$. Cup/disk oranı Parkinson grubunda $0,3 \pm 0,1$, kontrol grubunda $0,2 \pm 0,1$ idi $(\mathrm{p}=0.581)$.

Parkinson hasta grubu ve kontrol grubundaki tüm olgulara ait ortalama, süperior, temporal, inferior ve nazal kadran RSLT kalınlıkları tablo I'de, makula kalınlık değerleri ise tablo II'de verilmiştir. Gruplar karşılaştırıldığında sadece inferior kadran RSLT kalınlığı Parkinson grubunda kontrol grubuna kiyasla istatistiksel olarak anlamlı ince bulunmuştur ( $\mathrm{p}=0.049)$.

Tablo 1. Parkinson hasta grubunun ve kontrol grubunun ortalama ve her kadran RSLT kalınlık değerleri

\begin{tabular}{|lccc|}
\hline $\begin{array}{l}\text { RSLT } \\
\text { kadran }\end{array}$ & $\begin{array}{c}\text { Parkinson Hasta } \\
\text { grubu }\end{array}$ & $\begin{array}{c}\text { Kontrol } \\
\text { grubu }\end{array}$ & $\begin{array}{c}\mathrm{p}^{*} \\
\text { değeri }\end{array}$ \\
\hline Ortalama $(\mu \mathrm{m})$ & $110,3 \pm 12$ & $115,5 \pm 11,9$ & 0,160 \\
Süperior $(\mu \mathrm{m})$ & $131,7 \pm 15,6$ & $133,9 \pm 17,7$ & 0,661 \\
Temporal $(\mu \mathrm{m})$ & $78,5 \pm 14,7$ & $80,2 \pm 9,2$ & 0,663 \\
Inferior $(\mu \mathrm{m})$ & $133,1 \pm 19,3$ & $145,1 \pm 19,6$ & $\mathbf{0 , 0 4 9}$ \\
Nazal $(\mu \mathrm{m})$ & $97,7 \pm 18,9$ & $102,3 \pm 16,8$ & 0,404 \\
\hline & & & \\
\hline
\end{tabular}
RSLT: retina sinir lifi tabakası
Student t testi

Tablo 2. Parkinson hasta grubunun ve kontrol grubunun OKT ile saptanan makula kalınlık değerleri

\begin{tabular}{|c|c|c|c|}
\hline \begin{tabular}{|l|} 
Makula kadran \\
Kalınlığı \\
\end{tabular} & $\begin{array}{l}\text { Parkinson Hasta } \\
\text { grubu }\end{array}$ & $\begin{array}{l}\text { Kontrol } \\
\text { grubu }\end{array}$ & $\begin{array}{c}\mathrm{p}^{*} \\
\text { değeri }\end{array}$ \\
\hline Santral makula $(\mu \mathrm{m})$ & $206,7 \pm 22,3$ & $204,6 \pm 22,9$ & 0,756 \\
\hline Diş nasal $(\mu \mathrm{m})$ & $268,7 \pm 24,0$ & $267,1 \pm 16,4$ & 0,802 \\
\hline İç nasal $(\mu \mathrm{m})$ & $274,1 \pm 20,2$ & $273,5 \pm 17,6$ & 0,919 \\
\hline Diş üst $(\mu \mathrm{m})$ & $249,8 \pm 21,4$ & $250,9 \pm 13,5$ & 0,833 \\
\hline İç üst $(\mu \mathrm{m})$ & $275,8 \pm 19,5$ & $278,4 \pm 14,3$ & 0,619 \\
\hline Diș temporal $(\mu \mathrm{m})$ & $239,1 \pm 21,9$ & $245,5 \pm 15,6$ & 0,290 \\
\hline İç temporal $(\mu \mathrm{m})$ & $262,0 \pm 23,1$ & $265,2 \pm 16,2$ & 0,604 \\
\hline Diş alt $(\mu \mathrm{m})$ & $249,2 \pm 22,6$ & $251,7 \pm 14,2$ & 0,675 \\
\hline İç alt $(\mu \mathrm{m})$ & $271,7 \pm 23,2$ & $272,9 \pm 18,4$ & 0,852 \\
\hline
\end{tabular}

OKT:Optik koherens tomografi

*Student t-testi

\section{TARTIŞMA}

Biz yaptığımız bu çalışmada Parkinson hastalarında RSLT kalınlığında inferior kadranda incelme tespit ederken, ortalama ve diğer kadran RSLT ve makula kalınlık ölçümlerinde bir fark bulmadık. Literatürde Parkinson hastalarında RSLT ve makula kalınlığını inceleyen çalışmalarda bulunan sonuçlar değişkenlik göstermektedir ${ }^{7-14}$.

Inzelberg ve ark. ${ }^{7}$ Parkinson hasta grubunda inferior ve temporal kadran RSLT kalınlığında sağlıklı gruba kıyasla istatistiksel olarak anlamlı incelme saptamışlardır. Bayhan ve ark. ${ }^{8}$ ise nazal RSLT kalınlığında ve makular ganglion hücre kompleksinde incelme tespit etmişlerdir. $\mathrm{Bu}$ çalışmada aynı zamanda hastalık şiddeti ile ganglion hücre kompleks kalınlığı arasında ters korelasyon saptanırken, RSLT kalınlığı ile korelasyon tespit edilememiştir. Altıntaş ve ark. $^{9}$ ortalama, süperior ve nazal kadran RSLT'yi istatistiksel olarak anlamlı ince saptarken, fovea dıșındaki tüm makular 
alanlarda retinal kalınlık ve volümünde de azalma tespit etmişlerdir.

Moscos ve ark. ${ }^{10}$ ise RSLT kalınlığı ile birlikte makula fonksiyonunu multifokal elektroretinografi (mfERG) ile değerlendirdikleri çalışmalarında RSLT kalınlığını inferior ve temporal kadranda incelmiş saptarlarken, mfERG'de foveada elektriksel aktivitede azalma bulmuşlardır.

$\mathrm{Bu}$ çalışmaların sonuçlarının aksine Archibald ve ark. ${ }^{11} 51$ Parkinson hastasını 25 sağlıklı kontrol grubu ile karşılaştırdıkları çalışmalarında RSLT kalınlığı, foveal retinal kalınlık ve makular volüm açısından gruplar arasında fark bulmamışlardır. Bittersohl ve ark. ${ }^{12}$ ise Parkinson grubunda santral makular kalınlığı daha ince saptarlarken, makulanın diğer kadranları ve RSLT kalınlığında fark saptamamışlardır. Bu çalışmada aynı zamanda santral minimum makular kalınlık ile hastalık ciddiyeti arasında da ters korelasyon bulunmuștur. $\mathrm{Bu}$ nedenle Parkinson hastalarında RSLT'den ziyade makula bölgesinin özellikle de foveolanın daha önemli prognostik gösterge olabileceğini belirtmişlerdir.

Tsironi ve ark. ${ }^{13}$ ise Parkinson hasta grubunda görme alanı bozuklukları saptarken, RSLT kalınlığında değişiklik bulmamışlardır. Aeker ve ark. ${ }^{14}$ ise RSLT kalınlığı ve iç retina tabakası kalınlıkları arasında fark saptamazlarken, makula kalınlık incelemesinde 9 alandan 3'ünde Parkinson grubunda anlamlı incelme bulmuşlardır.

Parkinson hastalarında retinada dopamin miktarında azalma olduğu gösterilmiştir ${ }^{2}$. Dopamin eksikliğinin aksonlarıla RSLT'yi oluşturan ganglion hücrelerinde fonksiyon bozukluğuna yol açarak görsel işlev kaybına yol açabileceği düşünülmüştür ${ }^{16}$. Aynı zamanda dopamin retinada glutamat, gama aminobütirik asit ve glisin gibi nörokimyasalların etkinliğini kontrol etmede rol oynamaktadır. Azalmış dopaminerjik uyarının glutamat artışılla birlikte ganglion hücre kaybına yol açabileceği düşünülmüştür7.
Retinada bașlıca dopamin içeren kısım retina sinir lifi tabakası, ganglion hücre ve iç pleksiform tabakadan oluşan iç retina tabakasıdır $^{17}$. Hajee ve ark. ${ }^{18} 24$ Parkinson hastasıyla yaptıkları çalışmalarında makulada üst ve alt kadranda iç retina tabakası kalınlığını sağlıklı kontrol grubuna kıyasla daha ince saptamışlardır.

RSLT kalınlığında incelmenin görüldüğü durumlarda ayırıcı tanıda düşünülmesi gereken başlıca hastalık glokomdur. Glokom hastalığı göz içi basınç yüksekliği ile giden ganglion hücre harabiyetinin oluștuğu kronik progresif bir optik nöropatidir. OKT ile peripapiller RSLT kalınlık ölçümü glokom hastalığının tanı ve takibinde kullanılan yöntemlerden biri haline gelmiştir. Deneysel glokomda retina ganglion hücre ölümünün nörodejeneratif hastalıklardaki gibi apoptozis ile başladığı gösterilmiştir ${ }^{19}$. Apoptozisi tetikleyen şey glokomda genellikle artmış göz içi basıncı olmakla birlikte, göz içi basıncı kontrol altına alınmış hastalarda veya normal göz içi basıncına sahip kişilerde de hasarın görülmesi etiyopatogenezde başka faktörlerin de rol aldığını göstermektedir. Glokom bu açıdan vizüel sistemin nörodejeneratif hastalı̆̆l olarak düşünülmektedir ${ }^{20}$. Alzheimer ve Parkinson gibi nörodejeneratif hastalıklarda glokom sıklığının da artmış olduğu bildirilmiştir ${ }^{21}$. Bu nedenle bu hastalarda RSLT kalınlığında incelme gördügümüzde öncelikle glokomun dışlanması gerekmektedir. Çalışmamızda hastalarda göz içi basıncının normal aralıkta seyretmesi, optik sinirde genişlemiş cup, cup/disk asimetrisi gibi tipik glokomatöz değişikliklerin görülmemesi ile glokom dışlandı.

$\mathrm{Bu}$ çalışmada Parkinson hasta grubunda inferior kadran RSLT kalınlığında istatistiksel olarak anlamlı incelme tespit ederken, diğer kadran RSLT ve makula kalınlık değerlerinde bir fark saptamadık. Parkinson hastalarında retinadaki dopamin miktarında meydana gelen azalma ganglion hücre kaybına yol açarak RSLT kalınlığında incelmeye neden olabilmektedir. 
Literatürde RSLT ve makula kalınlığını inceleyen çalışmalarda sonuçların değişkenlik göstermesinin sebepleri arasında çalışmaların az sayıda hasta ile yapılmış olması, çalışmalara farklı yaş gruplarında, farklı hastalık şiddet ve sürelerinde hastaların dahil edilmiş olması ve farklı OKT cihazlarının kullanılmış olması sayılabilir. $\mathrm{Bu}$ nedenle daha büyük ve homojenize edilmiş hasta gruplarıyla yapılacak çalışmalar nörodejeneratif hastalık olan Parkinson'un RSLT ve makula kalınlığında değişime yol açıp açmadığı konusunda yardımcı olacaktır.

Çıkar Çatışması Beyanı: Yazarlar çıkar çatışması olmadığını bildirmişlerdir.

Finansal Destek: Bu çalışma her hangi bir fon tarafından desteklenmemiştir.

Declaration of Conflicting Interests: The authors declare that they have no conflict of interest.

Financial Disclosure: No financial support was received.

\section{KAYNAKLAR}

1. Aygül R, Demir R. Parkinson hastalığı tanı kriterleri. Turkiye Klinikleri J Neurol-Special Topics. 2012; 5: 537.

2. Harnois C, Di Paolo T. Decreased dopamine in the retinas of patients with Parkinson's disease. Invest Ophthalmol Vis Sci. 1990; 31: 2473-5.

3. Armstrong RA. Visual signs and symptoms of Parkinson's disease. Clin Exp Optom. 2008; 91: 129-38.

4. Ekinci C, Tuğcu B, Şen A. Parkinson hastalığında göz bulguları. MN Oftalmoloji. 2017; 24: 235-8.

5. Parisi V, Restuccia R, Fattapposta F, et al. Morphological and functional retinal impairment in Alzheimer's disease patients. Clin Neurophysiol. 2001; 112: 1860-7.

6. Parisi V, Manni G, Spadaro M, et al. Correlation between morphological and functional retinal impairment in multiple sclerosis patients. Invest Ophthalmol Vis Sci. 1999; 40: 2520-7.

7. Inzelberg R, Ramirez JA, Nisipeanu P, Ophir A. Retinal nerve fiber layer thinning in Parkinson disease. Vision Research. 2004; 44: 2793-7.

8. Bayhan HA, Bayhan SA, Tanık N, Gürdal C. The Association of Spectral-Domain Optical Coherence Tomography Determined Ganglion Cell Complex
Parameters and Disease Severity in Parkinson's Disease. Current Eye Research. 2014; 39: 1117-22.

9. Altintas O, Iseri P, Ozkan B, Caglar Y. Correlation between retinal morphological and functional findings and clinical severity in Parkinson's disease. Doc Ophthalmol. 2008; 116: 137-46.

10. Moschos MM, Tagaris G, Markopoulos I, et al. Morphologic changes and functional retinal impairment in patients with Parkinson disease without visual loss. Eur J Ophthalmol. 2011; 21: 24-9.

11. Archibald NK, Clarke MP, Mosimann UP, Burn DJ. Retinal thickness in Parkinson's disease. Parkinsonism Relat Disord. 2011; 17: 431-6.

12. Bittersohl D, Stemplewitz B, Keseru M, et al. Detection of retinal changes in idiopathic Parkinson's disease using high-resolution optical coherence tomography and heidelberg retina tomography. Acta Ophthalmol. 2015: 93: e578-e584.

13. Tsironi EE, Dastiridou A, Katsanos A, et al. Perimetric and retinal nerve fiber layer findings in patients with Parkinson's disease. BMC Ophthalmology. 2012; 12: 54.

14. Aaker GD, Myung JS, Ehrlich JR, et al. Detection of retinal changes in Parkinson's disease with spectraldomain optical coherence tomography. Clin Ophthalmol. 2010; 4: 1427-32.

15. Jankovic J. Parkinson's disease: clinical features and diagnosis. J Neurol Neurosurg Psychiatry. 2008 Apr; 79: 368-76).

16. Djamgoz MB, Hankins MW, Hirano J, Archer SN. Neurobiology of retinal dopamine in relation to degenerative states of the tissue. Vision Research. 1997; 37: 3509-29.

17. Frederick JM, Rayborn ME, Laties AM, Lam DM, Hollyfield JG. Dopaminergic neurons in the human retina. J Comp Neurol. 1982; 210: 65-79.

18. Hajee ME, March WF, Lazzaro DR, et al. Inner retinal layer thinning in Parkinson disease. Arch Ophthalmol. 2009; 127: 737-41.

19. Garcia-Valenzuela E, Shareef S, Walsh J, Sharma SC. Programmed cell death of retinal ganglion cells during experimental glaucoma. Exp Eye Res. 1995; 61: 33-44.

20. Balci SY, Eraslan M, Temel A. Glokom, Parkinson hastalığl ve nörodejenerasyon. Marmara Medical Journal. 2015; 28: 8-12.

21. Bayer AU, Keller ON, Ferrari F, Maag KP. Association of glaucoma with neurodegenerative diseases with apoptotic cell death: Alzheimer's disease and Parkinson's disease. Am J Ophthalmol. 2002; 133: 1357. 